\title{
Epidermal growth factor-like domain 7 (EGFL7) modulates Notch signalling and affects neural stem cell renewal
}

\section{Mirko H.H. Schmidt, Frank Bicker, Iva Nikolic, Jeannette Meister, Tanja Babuke, Srdjan Picuric, Werner Müller-Esterl, Karl H. Plate \& Ivan Dikic}

In the version of this article initially published online, the labelling of the boxes in Fig. $1 \mathrm{~b}$ was incorrect. In Fig. $1 \mathrm{~d}$ the mNotch 2 values were missing, in Fig. $1 \mathrm{~g}$ the Anti-EGFL7 was incorrectly labelled. In Fig 2c there was an extra ' + ' sign. In Fig 3d the title was incorrect. In Fig 5b the BSA label was missing from under the fifth bar. The correct versions of these figures are shown below. These errors have been corrected in the HTML and PDF versions of the article

Figure 1

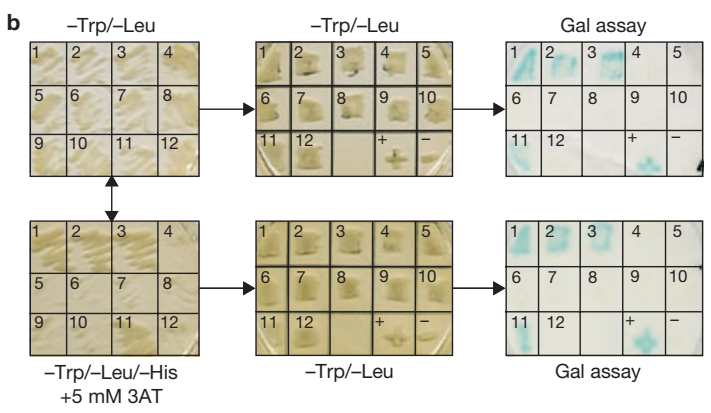

Figure 1

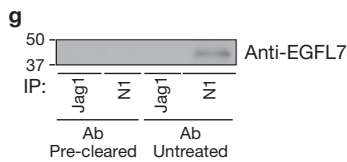

Figure 2

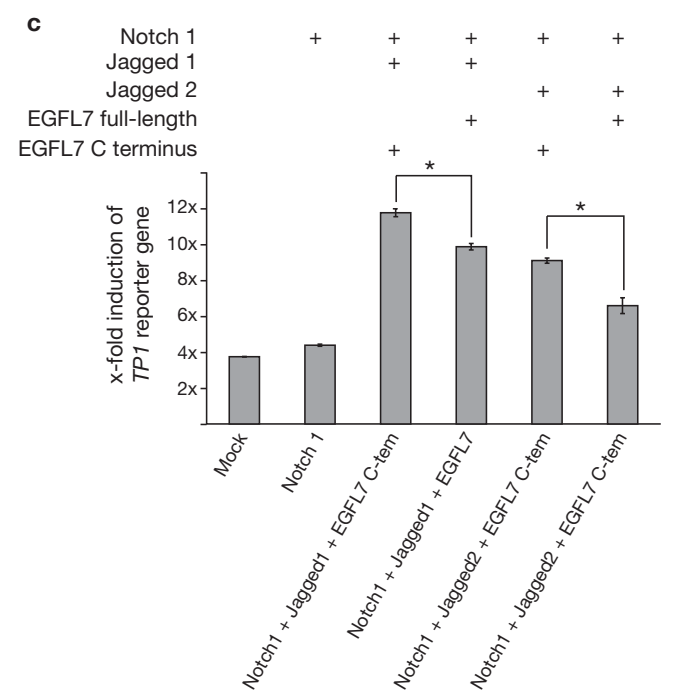

Figure 1

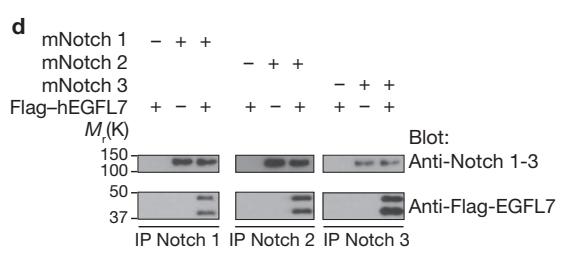

Figure 3

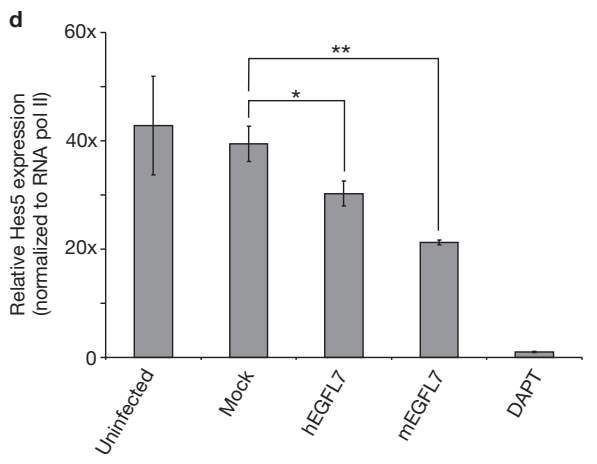

Figure 5

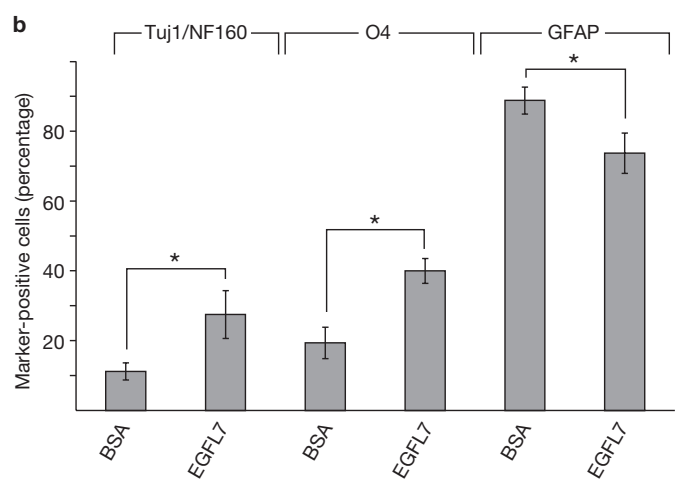

